\title{
TESTING OF MODULES FOR FACIAL RECOGNITION
}

\author{
N.Ramya ${ }^{1}$ \\ ${ }^{1}$ Department of Computer Science and Engineering, Koneru Lakshmaiah Education Foundation, \\ Vaddeswaram-522502, Guntur, AP, India
}
D.Manasa ${ }^{2}$
${ }^{2}$ Department of Computer Science and Engineering, Koneru Lakshmaiah Education Foundation, Vaddeswaram-522502, Guntur, AP, India

\author{
N.Ramya $\mathrm{Sri}^{3}$ \\ ${ }^{3}$ Department of Computer Science and Engineering, Koneru Lakshmaiah Education Foundation, \\ Vaddeswaram-522502, Guntur, AP, India
}

\author{
Sk.Naveed ${ }^{4}$ \\ ${ }^{4}$ Department of Computer Science and Engineering, Koneru Lakshmaiah Education Foundation, \\ Vaddeswaram-522502, Guntur, AP, India
}

Article DOI: https://doi.org/10.36713/epra5586

\begin{abstract}
Face is the crucial part of the human body that uniquely identifies a person. Using the face characteristics as biometric, the face recognition system can be implemented. The most demanding task in any organization is attendance marking. In traditional attendance system, the students are called out by the teachers and their presence or absence is marked accordingly. However, these traditional techniques are time consuming and tedious. In this project, the Open CV based face recognition approach has been proposed. This model integrates a camera that captures an input image, an algorithm for detecting face from an input image, encoding and identifying the face, marking the attendance in a spreadsheet and converting it into PDF file. The training database is created by training the system with the faces of the authorized students. The cropped images are then stored as a database with respective labels. The features are extracted using $\mathrm{LBPH}$ algorithm.
\end{abstract}

\section{INTRODUCTION}

Attendance maintenance is a significant function in all the institutions to monitor the performance of the students. Every institute does this in its own way. Some of these institutes use the old paper or file based systems and some have adopted strategies of automatic attendance using some biometric techniques. A facial recognition system is a computerized biometric software which is suited for determining or validating a person by performing comparison on patterns based on

$$
\text { (c) } 2020 \text { EPRA IJRD | Journal DOI: https://doi.org/10.36713/epra2016 | www.eprajournals.com |132 | }
$$




\section{SJIF Impact Factor: 7.001| ISI I.F.Value:1.241| Journal DOI: 10.36713/epra2016 ISSN: 2455-7838(Online) EPRA International Journal of Research and Development (IJRD)

their facial appearances. Face recognition systems have upgraded appreciably in their management over the recent years and this technology is now vastly used for various objectives like security and in commercial operations. Face recognition is a powerful field of research which is a computer based digital technology. Face recognition for the intent of marking attendance is a resourceful application of attendance system. It is widely used in security systems and it can be compared with other biometrics such as fingerprint or eye iris recognition systems. As the number of students in an educational institute or employees at an organization increases, the needs for lecturers or to the organization also increase the complication of attendance control. This project may be helpful for the explanation of these types of problems. The number of students present in a lecture hall is observed, each person is identified and then the information about the number of students who are present I maintained.

The enhancement of science and technology leads to make the life more comfortable than older days. The emerging technologies like neutrosophic shortest path $[1,2,3,4,5]$, transportation problem $[6,7,8]$, uncertainty problem $[9,10,11,12,13,14]$, fuzzy shortest path $[15,16,17,18,19]$, PowerShell [20], wireless sensor network $[21,22,23,24,25,26,27,28]$, computer language [29,30], neural network [31], routing [32] making the products more intelligent and self-healing based. The smart city applications like smart water, smart grid, smart parking, smart resource management, etc. are based on IoT and IoE $[33,34,35,36]$ technologies. We have the development available to us to enable the organization of our consistently lives and the sharing of significant information with our associates, families and others. Why development is huge in our consistently life. It is a basic contraption that we can't avoid, it has a huge impact in the vast majority of our lives Technology fundamentally handles the instruments, advancements and strategies used to help us with dealing with issues and simply improve our everyday schedules and easier to encounter to a great extent [37,38]. Advancement is inevitable in our normal everyday presences [39]. This is in light of the fact that presence without advancement is senseless in the present incredible world. Development, which joins instruments to propel unforeseen development, use and information exchange, has as its basic objective of making tasks easier and the handling of various issues of mankind. Right when development advances and makes our continues with extensively more worthwhile, we should pressure that it is so useful to our lives.

\section{ALGORITHM}

There are various algorithms used for facial recognition. Some of them are as follows: 1. Eigen faces 2. Fisher faces 3. Local binary patterns histograms

1. EIGEN FACES This method is a statistical plan. The characteristic which influences the images is derived by this algorithm. The whole recognition method will depend on the training database that will be provided. The images from two different classes are not treated individually.

2. FISHER FACES Fisher faces algorithm also follows a progressive approach just like the Eigen faces. This method is a alteration of Eigen faces so it uses the same principal Components Analysis. The major conversion is that the fisher faces considers the classes. As mentioned previously, the Eigen faces does not differentiate between the two pictures from two differed classes while training. The total average affects each picture. A Fisher face employs Linear Discriminant Analysis for distinguishing between pictures from a different class.

3. LOCAL BINARY PATTERNS HISTOGRAMS This method needs the gray scale pictures for dealing with the training part. This algorithm in comparison to other algorithms is not a holistic approach.

I. PARAMETERS: LBPH uses the following parameters: i. Radius: Generally 1 is set as a radius for the circular local binary pattern which denotes the radius around the central pixel.

II. Neighbors: The number of sample points surrounding the central pixel which is generally 8.The computational cost will increase with increase in number of sample points.

III. Grid X: The number of cells along the horizontal direction is represented as Grid X. With the increase in number of cells the grid becomes finer which results in increase of dimensional feature vector.

IV. Grid Y: The number of cells along the vertical direction is represented as Grid Y. With the increase in number of cells the grid becomes finer which results in increase of dimensional feature vector.

\section{B. ALGORITHM TRAINING}

For the training purpose of the dataset of the facial images of the people to be recognized along with the unique ID is required so that the presented approach will utilize the provided information for perceiving an 
input image and providing the output. Same images require same ID.

\section{COMPUTATION OF THE ALGORITHM}

The intermediate image with improved facial characteristics which corresponds to the original image is created in the first step. Based on the parameters provided, sliding window theory is used in order to achieve so. Facial image is converted into gray scale. A $3 \times 3$ pixels window is taken which can also be expressed as a $3 \times 3$ matrix which contains the intensity of each pixel (0-255). After this we consider the central value of the matrix which we take as the threshold. This value defines the new values obtained from the 8 neighbours. A new binary value is set for each neighbour of the central value. For the values equal to or greater than the threshold value 1 will be the output otherwise 0 will be the output. Only binary values will be present in the matrix and the concatenation is performed at each position to get new values at each position. Then the conversion of this binary value into a decimal value is done which is made the central value of the matrix. It is a pixel of the actual image. As the process is completed, we get a new image which serves as the better characteristics of the original image. D. EXTRACTION OF HISTOGRAM: The image obtained in the previous step uses the Grid $\mathrm{X}$ and Grid $\mathrm{Y}$ parameters and the image is split into multiple grids. Based on the image the histogram can be extracted as below: 1. The image is in gray scale and each histogram will consist of only 256 positions $(0-255)$ which symbolises the existences of each pixel intensity. 2. After this each histogram is created and a new and bigger histogram is done. Let us suppose that there are $8 \mathrm{x} 8$ grids, then there will be 16.384 positions in total in the final histogram.

\section{Face Recognition}

The training of the algorithm is done. For finding the image which is same as the input image, the two histograms are compared and the image corresponding to the nearest histogram is returned. Different approaches are used for the calculation of distance between the two histograms. Here we use the Euclidean distance based on the formula: Hence the result of this method is the ID of the image which has the nearest histogram. It should return the distance calculated in the form of 'confidence'. Then the threshold and the 'confidence' can be used to automatically evaluate if the image is correctly recognized. If the confidence is less than the given threshold value, it implies that the image has been well recognized by the algorithm.

\begin{tabular}{|c|c|c|}
\hline ACE & FACE & \\
\hline $\begin{array}{c}\text { Confidence factor } \\
\text { based on output } \\
\text { is 2,000-3,000. }\end{array}$ & It is 100-400. & \\
\hline $\begin{array}{c}\text { Threshold value } \\
\text { is 4,000. }\end{array}$ & $\begin{array}{c}\text { Threshol value } \\
\text { d is } 400\end{array}$ & Threshold value is 7. \\
\hline $\begin{array}{c}\text { Principle of } \\
\text { dataset } \\
\text { generation } \\
\text { is }\end{array}$ & $\begin{array}{c}\text { It is component } \\
\text { based. }\end{array}$ & It is pixel based. \\
$\begin{array}{c}\text { component } \\
\text { based. }\end{array}$ & & \\
\hline $\begin{array}{c}\text { Basic principl is } \\
\text { PCA. }\end{array}$ & $\begin{array}{c}\text { Basic principle } \\
\text { is LDA. }\end{array}$ & $\begin{array}{c}\text { Basic principle is } \\
\text { Histogram. }\end{array}$ \\
\hline $\begin{array}{c}\text { Background } \\
\text { noise is } \\
\text { maximum. }\end{array}$ & $\begin{array}{c}\text { Background } \\
\text { noise is } \\
\text { medium. }\end{array}$ & $\begin{array}{c}\text { Background noise is } \\
\text { minimum. }\end{array}$ \\
\hline $\begin{array}{c}\text { Efficiency } \\
\text { is } \\
\text { minimum. }\end{array}$ & $\begin{array}{c}\text { Efficiency is } \\
\text { Greater than } \\
\text { Eigen } \\
\text { face. }\end{array}$ & $\begin{array}{c}\text { Efficiency } \\
\text { maximum. }\end{array}$ \\
\hline
\end{tabular}

Table 1. Comparison of LBPH with other algorithms 


\section{SJIF Impact Factor: 7.001| ISI I.F.Value:1.241| Journal DOI: 10.36713/epra2016 ISSN: 2455-7838(Online)}

\section{EPRA International Journal of Research and Development (IJRD)}

Volume: 5 | Issue: 11 | November 2020

- Peer Reviewed Journal

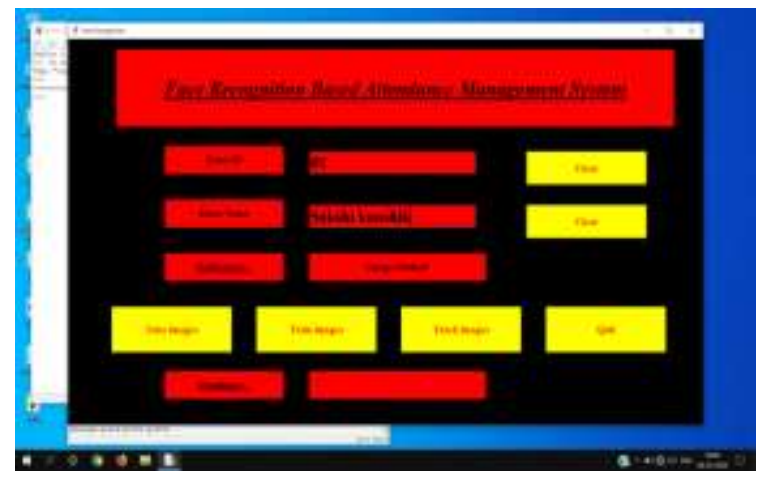

\section{CONCLUSION}

The conclusion of the project is the most productive Open $\mathrm{CV}$ face recognition method accessible for Attendance Management. The system has been implemented using algorithm It excels other algorithms by confidence factor of 2-5 and has least noise interference. The implementation of the Smart Attendance System portrays the existence of an agreement between the appropriate recognition rate and the threshold value. Therefore is the most authentic and competent face recognition algorithm found in Open CV for the identification of the students in an educational institute and marking their attendance adequately by averting proxies?

\section{REFERENCES}

1. Broumi, S., Dey, A., Talea, M. et al. Shortest path problem using Bellman algorithm under neutrosophic environment. Complex \& Intelligent Systems, 5 (2019), 409-416.

2. Kumar, R., Dey, A., Broumi, S., and Smarandache, F. A study of neutrosophic shortest path problem. In Neutrosophic Graph Theory and Algorithms. IGI Global, 2020.

3. Kumar, R., Edalatpanah, S. A., Jha, S., Broumi, S., Singh, R., and Dey, A. A multi objective programming approach to solve integer valued neutrosophic shortest path problems. Neutrosophic Sets and Systems, 24 (2019), 139151.

4. Kumar, R., Edalatpanah, S. A., Jha, S., and Singh, R. A novel approach to solve gaussian valued neutrosophic shortest path problems. International Journal of Engineering and Advanced Technology, 8 (2019), 347-353.

5. Kumar, R., Edaltpanah, S. A., Jha, S., Broumi, S., and Dey, A. Neutrosophic shortest path problem. Neutrosophic Sets and Systems, 23 (2018), 5-15.

6. Pratihar, J., Kumar, R., Dey, A., and Broumi, S.

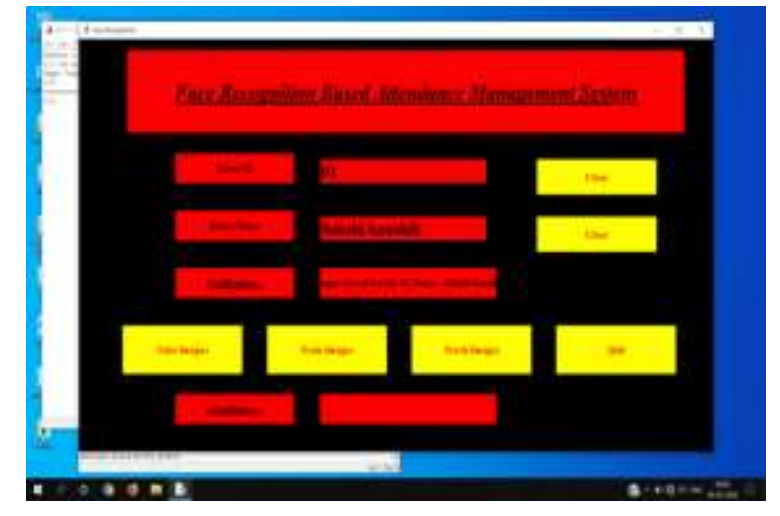

\section{ce for proposed model}

Transportation problem in neutrosophic environment. In Neutrosophic Graph Theory and Algorithms. IGI Global, 2020.

7. Kumar, R., Edalatpanah, S. A., Jha, S., and Singh, R. A Pythagorean fuzzy approach to the transportation problem. Complex \& Intelligent Systems, 5 (2019), 255-263.

8. Pratihar, J., Kumar, R., Edalatpanah, S. A., and Dey, A. Modified Vogel's approximation method for transportation problem under uncertain environment. Complex \& Intelligent Systems (2020), 1-12.

9. Gayen, S., Jha, S., Singh, M., and Kumar, R. On a generalized notion of anti-fuzzy subgroup and some characterizations. International Journal of Engineering and Advanced Technology, 8 (2019), 385-390.

10. Gayen, S., Smarandache, F., Jha, S., and Kumar, $R$. Interval-valued neutrosophic subgroup based on interval-valued triple t-norm. In Neutrosophic Sets in Decision Analysis and Operations Research. IGI Global, 2020.

11. Gayen, S., Smarandache, F., Jha, S., Singh, M. K., Broumi, S., and Kumar, R. Introduction to plithogenic subgroup. In Neutrosophic graph Theory and Algorithms. IGI Global, 2020.

12. Gayen, S., Smarandache, F., Jha, S., Singh, M. $K$. , Broumi, S., and Kumar, R. Soft Subring Theory Under Interval-valued Neutrosophic Environment. Neutrosophic Sets and Systems, 36 (2020), 16.

13. Gayen, S., Smarandache, F., Jha, S., and Kumar, $R$. Introduction to interval-valued neutrosophic subring. Neutrosophic Sets and Systems, 36 (2020), 17.

14. Gayen, S., Smarandache, F., Jha, S., Singh, M. K., Broumi, S., and Kumar, R. Introduction to plithogenic hypersoft subgroup. Neutrosophic Sets and Systems, 33 (2020), 208-233.

15. Kumar, R., Edalatpanah, S. A., and Mohapatra, H. Note on "Optimal path selection approach for 


\section{SJIF Impact Factor: 7.001| ISI I.F.Value:1.241| Journal DOI: 10.36713/epra2016 ISSN: 2455-7838(Online) EPRA International Journal of Research and Development (IJRD)

fuzzy reliable shortest path problem “. Journal of Intelligent \& Fuzzy Systems (2020), 1-4.

16. Kumar, R., Jha, S., and Singh, R. A different approach for solving the shortest path problem under mixed fuzzy environment. International Journal of Fuzzy System Applications, 9 (2020), 132-161.

17. Kumar, R., Jha, S., and Singh, R. Shortest path problem in network with type-2 triangular fuzzy arc length. Journal of Applied Research on Industrial Engineering, 4 (2017), 1-7.

18. Kumar, Ranjan, Edalatpanah, S. A., Jha, Sripati, Gayen, Sudipta, and Singh, Ramayan. Shortest path problems using fuzzy weighted arc length. International Journal of Innovative Technology and Exploring Engineering, 8 (2019), 724-731.

19. Kumar, R., Edalatpanah, S. A., Jha, S., Gayen, S., and Singh, R. Shortest path problems using fuzzy weighted arc length. International Journal of Innovative Technology and Exploring Engineering, 8 (2019), 724-731.

20. Mohapatra, H., Panda, S., Rath, A. K., Edalatpanah, S. A., and Kumar, R. A tutorial on powershell pipeline and its loopholes. International Journal of Emerging Trends in Engineering Research, 8 (2020), 975-982.

21. Mohapatra, H., Rath, S., Panda, S., and Kumar, $R$. Handling of man-in-the-middle attack in wsn through intrusion detection system. International Journal of Emerging Trends in Engineering Research, 8 (2020), 1503-1510.

22. Mohapatra, H., Debnath, S., and Rath, A. K. Energy management in wireless sensor network through eb-leach. International Journal of Research and Analytical Reviews, 56 (2018), 56 61.

23. Mohapatra, H., Rath, A. K., Landge, P. B., Bhise, D., Panda, S., and Gayen, S. A comparative analysis of clustering protocols of wireless sensor network. International Journal of Mechanical and Production Engineering Research and Development, 10 (2020), 8371-8386.

24. Mohapatra, H. and Rath, A. K. A survey on fault tolerance based clustering evolution in wsn. IET Networks (2020).

25. Mohapatra, H., Debnath, S., Rath, A. K., Landge, P. B., Gayen, S., and Kumar, R. An efficient energy saving scheme through sorting technique for wireless sensor network. International Journal of Emerging Trends in Engineering Research, 8 (2020), 4278-4286.

26. Mohapatra, H. and Rath, A. K. Fault tolerance in wsn through uniform load distribution function. International Journal of Sensors, Wireless Communications and Control, 10 (2020).

27. Mohapatra, H. and Rath, A. K. Fault tolerance through energy balanced cluster formation (ebcf) in wsn. In Smart Innovations in Communication and Computational Sciences ( 2018), springer, 313-321.

28. Mohapatra, Hitesh and Rath, Amiya Kumar. Fault tolerance in WSN through PE-LEACH protocol. IET Wireless Sensor Systems, 9, 6 (Dec. 2019), 358-365(7).

29. Mohapatra, H. C Programming: Practice. Amazon, 2018.

30. Mohapatra, H. and Rath, A. K. Fundamentals of Software Engineering. BPB, 2020.

31. Mohapatra, H. HCR by Using Neural Network. 2009.

32. Panda, M., Pradhan, P., Mohapatra, H., and Barpanda, N. K. Fault tolerant routing in heterogeneous environment. International Journal of Scientific \& Technology Research, 8 (2019), 1009-1013.

33. Mohapatra, H. Offline drone instrumentalized ambulance for emergency situations. International Journal of Robotics and Automation, 9 (2020), 251-255.

34. Mohapatra, H. and Rath, A. K. Detection and avoidance of water loss through municipality taps in india by using smart tap and ict. IET Wireless Sensor Systems (2019), https--doi.

35. Panda, H., Mohapatra, H., and Rath, A. K. Wsnbased water channelization: an approach of smart water. In Smart Cities: Opportunities and Challenges. Springer, Singapore, 2020.

36. Rout, S. S., Mohapatra, H., Nayak, R. K., Tripathy, R., Bhise, D., Patil, S. P., and Rath, A. $K$. Smart water solution for monitoring of water usage based on weather condition. International Journal of Engineering and Technical Research, $8 \quad$ (2020), 5335-5343. 